\title{
The Relationship between Implicit and Explicit Knowledge and Second Language Proficiency
}

\author{
Bahareh Esteki \\ Department of English, Faculty of Foreign Languages, University of Isfahan, Iran
}

\begin{abstract}
Implicit and explicit knowledge as two important concepts have long been at the center of attention in second language research. In this paper, first of all some theoretical backgrounds about the nature of linguistic knowledge and implicit and explicit L2 knowledge, interface issue and its pedagogical implications, and operational definition of implicit and explicit L2 grammatical knowledge were presented. And then, previous studies about the two types of knowledge and L2 proficiency operationalized in different ways were discussed. The results showed that the relationship between explicit knowledge and L2 proficiency is still not clear and previous investigations have found mix results concerning this relationship. Therefore, future investigations are needed to better probe the relationship between explicit knowledge and $L 2$ proficiency in second language learning.
\end{abstract}

Index Terms - implicit knowledge, explicit knowledge, language proficiency

\section{INTRODUCTION}

Implicit and explicit knowledge as two important concepts have long been at the center of attention in second language research. Implicit knowledge of an L2 is defined as tacit, intuitive, procedural, which is target as well as nontarget like, and is only observable when second language learners are communicating. On the other hand, explicit knowledge is conscious, declarative, is likely to be inaccurate, and can be verbalized. Language proficiency is defined as "a person's overall competence and ability to perform in L2 [Second Language]" (Thomas, 1994, p. 330). There is evidence in SLA research to consider grammar as one of the main components of L2 proficiency (e.g., Oller, 1979). Therefore, the purpose of present paper was to mention some theoretical backgrounds about implicit and explicit L2 knowledge and language proficiency, and also to qualitatively answer the question of the relationship between implicit and explicit knowledge and L2 proficiency.

\section{THEORETICAL BACKGROUND}

There are two views concerning nature of linguistic knowledge as mentioned by Ellis (2005). The first view refers to Chomsky's universal principles which are applicable to all languages and some parameters which are language specific working one behind the other to give rise to a specific language from poor input. According to this view, positive evidence or input activates principles and parameters to drive a person's linguistic knowledge. The Second view which is related to the works of connectionists theories of language learning does not make a difference between language knowledge and other kinds of knowledge and considers linguistic knowledge as an outcome of bit by bit abstraction of rules manifested by frequency and likeliness of happening of from/ function mappings. The above mentioned rules are achieved by having a long term experience of learning a language.

Based on this approach "linguistic knowledge emerges gradually as learners acquire new sequences, restructure their representation of old sequences, and, over time, extract underlying patterns that resemble rules" (Ellis, 2005, p. 142). As a result, second language researchers have controversy over determining which two views authentically demonstrate the nature of linguistic knowledge. Learning a language needs both of these two types of linguistic knowledge. Although there is a big difference between the two positions towards the nature of linguistic knowledge, the distinction between implicit and explicit knowledge is a characteristic which both connectionist and Chomskian positions have agreement upon.

\section{IMPLICIT AND EXPLICIT L2 KNOWLEDGE}

Second language researchers as well as cognitive psychologists have long acknowledged the value of implicit explicit learning and knowledge as an important and ongoing subject in second language research. Whereas, some cognitive researchers have rejected the authenticity of making differences between both implicit and explicit learning and knowledge, other researchers increasingly prefer different systems of learning and knowledge. Illumination of making a distinction between implicit and explicit learning as well as implicit and explicit knowledge is essential and necessary. The first one is related to the processes engaged in learning a language, but the second one is related to the product of language learning (Ellis et al., 2009). Both attention and awareness in learning a language lay claim of the distinction between implicit and explicit knowledge. As a result, implicit learning refers to the learning which comes about without 
either attention or awareness. But, there is disagreement about the likeliness of such a learning to take place. For instance, Schmidt (2001) states that "people learn about the things that they attend to and don't learn much about things that they don't attend to" (p. 30). The distinction between implicit and explicit learning has kept being an important concept among most second language researchers, despite those debates. Although, up to now, there are few investigations aimed at probing the distinction between implicit and exploit knowledge which consider processes and devices engaged in second language acquisition, there are more studies by second language researchers that have examined the distinction between implicit and explicit knowledge. Second language researchers have used different testing instruments to probe the state and of implicit and explicit knowledge which are accepted to draw learners' implicit and explicit knowledge. Despite controversies concerning the validity of these test, some researchers tried to determine the construct validity of such tests to guarantee their use as valid and reliable measures of implicit and explicit knowledge. The testing instruments used by second language researchers are a timed and an untimed grammaticality judgment tests (TGJT)/ (UGJT), an elicited oral imitation test EIT, and a metalinguistic test (MKT). The TGJT and EIT were designed to draw learners' implicit knowledge and UGJT and MKT were designed to tap on learners' explicit knowledge. According to Ellis et al. (2009), it is assumed that TGJT taps on learners' implicit knowledge. In a usual TGJT, learners are given a number of grammatical as well as ungrammatical sentences and are required to find out grammaticality of sentences, that is, to determine which sentence is grammatical and which sentence is ungrammatical. Although in UGJT learners are asked to determine the grammaticality of each sentence with no time limit, in TGJT learners are required to determine the grammaticality of each sentence within time limit. In other words, this time limit prevents learners from using their explicit knowledge which needs ample time. Any testing instrument which puts learners under time pressure and requires learners to assess the language immediately and very fast has the probability of drawing learners' implicit knowledge and any testing instrument of the second language which gives learners lots of time to arrange their language knowledge and pay learners' attention to the language forms is likely to draw learners' explicit knowledge. In EIT first learners are required to say whether they agree or disagree with the content of each sentence and then are asked to produce each sentence in correct English. In this way, learners draw on their implicit knowledge. In contrast, UGJT causes learners to tap on their explicit knowledge mostly due to the fact that there is lots of time to determine the grammaticality of sentences and also learners are required to centre their attention on formal features of language. Likewise, a MKT, which asks learners to explain the reasons and the rules about the grammaticality of each sentence, must tap on learners' explicit knowledge. Based on Ellis et al. (2009), EIT can be considered as a measure of implicit knowledge because high correlation between scores on EIT and other measures of implicit knowledge has been found.

Krashen (1981) tried to distinguish between acquired and learned knowledge. Implicit knowledge is defined as the knowledge which is tacit and procedural and can be obtained without thinking about it in spontaneous tasks and cannot be verbalized. In contrast, explicit knowledge is conscious and declarative and is available by utilization of attentional processes and can be verbalized by individuals (Bowles, 2011; Ellis, 2005). Based on Ellis (1991) "implicit and explicit knowledge are held to be different in kind and to be stored separately in the brain" (p. 182).

\section{THE INTERFACE ISSUE}

There are debates concerning the interface between implicit and explicit knowledge. The interface issue answers questions such as: Whether implicit and explicit knowledge are related to each other or not? Is it possible for explicit knowledge to be converted into implicit knowledge? There are three answers which have been given to the interface issue:

1. According to strong interface position, when learners practice and use explicit and declarative linguistic rules, explicit knowledge can be converted into implicit knowledge. That is, by practice and rehearsal learners are able to first learn a linguistic rule as declarative fact and then convert that linguistic rule to implicit knowledge (Ellis et al., 2009).

2. According to non-interface position, implicit and explicit knowledge are stored separately in different parts in the brain and demands strict different mechanism and, as a result, can't be converted to each other.

3. According to weak interface position, explicit knowledge can help the acquisition of implicit knowledge by causing some aspect of input more salient and outstanding to learners. There are three versions of weak interface position. One version posits that explicit knowledge can be converted into implicit knowledge when learners are developmentally are prepared to acquire the linguistic rule. The second version states that explicit knowledge can help the acquisition of implicit knowledge indirectly by assisting the required and necessary conditions for the acquisition of implicit knowledge. For instance, explicit knowledge can cause some parts of input more noticeable to learners and as a result facilitate the acquisition of implicit knowledge. The third version posits that "learners can use their explicit knowledge to produce output then serves as auto-input to their implicit learning mechanisms" (Ellis et al., 2009, p. 22).

\section{PedAgogical IMPLiCATIONS FOR THE INTERFACE POSITIONS}

There are some pedagogical implications for the interface positions for second language learning and teaching. None-interface position suggests an empirical and analytical approach towards second language teaching which attempts to provide learners with lots of L2 input without any explicit teaching of grammatical rules. However, those 
who argue in favor of strong interface position see a role for explicit language teaching and knowledge assuming that second language learners can to change their declarative, concuss knowledge into implicit knowledge which is beneficial and can be used in real and on line communication. Weak interface position, in contrast, suggests that to some extent explicit grammatical teaching can be useful for second language acquisition through causing some features of the input more noticeable and outstanding to L2 learners.

\section{OPERATIONALIZING IMPLiCIT AND EXPLICIT L2 GRAMMATICAL KNOWLEDGE}

Second language acquisition researchers have the problem of reliable and valid measures of both implicit and explicit knowledge as stated by Ellis (2005). According to Douglas (2001), lack of valid and reliable measures is general in SLA. As Douglas (2001) mentioned construct validity can be accomplished by "the construction of theoretical arguments linking hypothesized aspects of language ability to features of test task" (p. 447). As a result, having a theoretical framework which serves to the operational definitions of implicit and explicit knowledge is necessary.

There are agreements among SLA researchers in the field about the following criteria in order to differentiate between tacit and procedural knowledge (For example, krashen, 1982; Ellis et al., 2009).

1. Degree of awareness: Learners are not normally aware of their implicit knowledge; however using explicit knowledge involves rule awareness.

2. Times available: when individuals are under time pressure to carry out a task immediately, Implicit knowledge can be derived, however tasks without time pressure would let individuals to tap both on their explicit and implicit knowledge.

3. Focus of attention: Using implicit knowledge involves a special focus on meaning and peripheral focus on language form; however utilizing explicit knowledge needs a particular focus on language form and a peripheral focus on message.

In this direction, according to Ellis et al. (2009), any operational definition of implicit and explicit knowledge should entail the following seven features:

(1) Degree of awareness: To what extent learners are aware of and know about their linguistic knowledge? This linguistic knowledge can be measured by questioning learners to mention whether their response to an item is born out of knowledge of rule or only by feeling.

(2) Time available: Tasks which are performed under time pressured do not permit learners to tap on their explicit knowledge and as a result call learners to utilize the knowledge which is accessible in terms of procedural knowledge without much difficulty.

(3) Focus of attention: Because of narrow processing capability, it is hard for learners to center their attention on both meaning and from. Implicit knowledge does not demand learners to form and put the processing capability to focus on message.

(4) Systematicity: There is more uniformity for learners in a task that asks them to utilize their implicit knowledge than in a task than asks learners to utilize their declarative knowledge.

(5) Certainty: There are learners who have more assurance in utilizing their declarative knowledge in answering a task, and also there are some learners who have more confidence in their procedural knowledge while doing a task.

(6) Metalanguage: Learners are only able to tap on their explicit knowledge to mention metalinguistic comments and rules.

(7) Learnability: Form-focused language teaching which benefits adult learners more than children normally leads to declarative L2 knowledge, while meaning-focused and communicative language teaching particularly when instructed at children leads to more implicit knowledge.

Therefore, by manipulation and use of the above-mentioned criteria it is likely to make testing instruments which draw learners' either procedural or declarative knowledge. To put it differently, a measurement instrument which taps on learners' attention to particular grammatical structures while giving them lots of time is probable to leads to learners' explicit knowledge. A test which, in contrast, leaves learners under pressure to convey the message under usual processing limitations most possibly draws learners' tacit knowledge.

\section{LANGUAGE PROFICIENCY}

There have been almost no agreements about the definition of second language proficiency among the researchers or the professionals in language assessment area. Not only is the definition of language proficiency independent of the language user, but also it is connected to the language user's background. For instance, Briere (1972) defines language proficiency as "the degree of competence or the capability in a given language demonstrated by an individual at a given point in time independent of specific textbook, chapter in book, or pedagogical method" (p. 322). According to Richards (1985, as cited in McArthur, 1992) language proficiency is the level of skill and capability that someone is able to use to perform in a language. In this direction, Clark (1975) mentions that LP is the use of language for real life purposes without any concentration to the way in which that the knowledge and ability is accomplished. Farhady (1983) criticized the above definitions for not taking into account some important parameters. 
Based on Bachman (1990), the previous frameworks for describing language proficiency testing were skills and components model such as what has been offered by Lado (1961) and Carroll (1961) in the early 1990s. Such models differentiated between skills (listening, speaking, reading, and writing) and components of knowledge (grammar, vocabulary, phonology), however did not realize language use's total contexts. Besides, Hymes (1972) suggested the inclusion of discoursal and sociocultural factors into a definition of communicative competence. But, In the 1980s, the original study conducted by Canale and Swain (1980) was the turning point in all the debates of communicative competence. Canale and Swain (1980) and later Canale (1983), suggest a set of four subcategories, or competences, which constitute the concept of communicative competence. These include grammatical competence, discourse competence, sociolinguistic competence, and strategic competence.

\section{The Relationship Between Implicit And Explicit L2 GrammaticAl KNOWLEDGE AND SeCOND LANGUAGE PROFICIENCY}

There is agreement about the role of implicit knowledge in second language acquisition. As for explicit knowledge, there are a number of studies that have investigated the relationship between explicit knowledge and second language proficiency. Sorace (1985) investigated the explicit knowledge of two intact groups of L2 learners of Italian and discovered that they did better in oral production tasks if they had a good command of explicit knowledge. Alderson, Clapham, and Steel (1997) in a study measuring L2 proficiency and explicit knowledge of French students, showed that there are low correlations between the two tests of explicit knowledge and L2 proficiency. This positive correlation was also discovered in a study by Renou (2001) who examined the relationship between metalinguistic knowledge and French L2 proficiency of sixty-four university-level L2 learners whose first language was English. Although a positive correlation between explicit knowledge of third-person singular possessive determiners and performance in an openended oral production task was discovered by White and Ranta (2002) for both control group as well as treatment group before instruction, the correlation between explicit knowledge and the oral production task was not statistically significant for the treatment group after teaching of those grammatical structures. Hu (2002) discovered that learners function superior in spontaneous writing tasks if they had the knowledge of some English grammatical structures. In a study examining the relationship between performance and explicit knowledge, Elder and Manwaring (2004) uncovered that more metalinguistic knowledge resulted in better performance and functioning for some participants in their study. In a study investigating the relationship between metalinguistic knowledge and L2 proficiency of five intact groups of learners, three freshman groups and two senior groups, Roehr (2008) discovered that there is a strong positive correlation between the two variables. Elder (2009) examined that although different sections of Test of English as a Foreign Language (TOEFL) and the International English Language Testing System (IELTS) have significant correlations with a metalinguistic knowledge test, this correlation was not found between the Diagnostic English Language Needs Assessment (DELNA) and MLK. To explain the last result, Elder mentioned that because learners were of high language proficiency, it is likely that they used their implicit knowledge in last English proficiency test.

There are few studies that have investigated the relationship between implicit and explicit knowledge and L2 proficiency. Han and Ellis (1998) probed the relationship between implicit and explicit knowledge and L2 proficiency operationalized by the TOEFL and the Secondary Level English Proficiency Test - SLEP. They found that Secondary Level English Proficiency Test correlated with measures of implicit as well as explicit knowledge whereas Test of English as a Foreign Language correlated only with explicit knowledge. They attributed the results to the nature of TOEFL which is more likely to elicit explicit knowledge. In another two studies by Elder and Ellis (2009), they investigated the relationship between implicit and explicit L2 grammatical knowledge and L2 proficiency operationalized by TOEFL and IELTS. In the first study, they found that TOEFL correlated with all measures of explicit knowledge, but in the second study measures of explicit as well as implicit knowledge correlated with IELTS. Elder and Ellis suggested three explanations for the different result between the two studies. The first is that the two tests of TOEFL and IELTS elicit two different type of knowledge. The second one is that in the first study, they used only Timed Grammatical Judgment Test as a measure of implicit knowledge, but in the second study, they used both Elicited Oral Imitation Test and Timed GJT as measures of implicit knowledge. And the last one is that in the first study, they used total score for measures of both implicit and explicit knowledge, but in the second study, the scores for seventeen grammatical structures for all measures of implicit and explicit knowledge was calculated and used by the authors. Therefore, further research is needed to investigate the relationship between implicit and explicit knowledge and L2 proficiency.

\section{CONCLUSION}

Alderson et al. (1997) and Elder, Warren, Hajek, Manwaring, and Davies (1999) found low and moderate relationships between metalinguistic knowledge and language proficiency. However, Elder and Manwaring (2004) and Roehr (2008) found positive correlation between explicit knowledge and L2 proficiency, and Elder and Ellis (2009) also found that explicit knowledge correlated with the TOEFL test. In two studies done by Sorace (1985) and White and Ranta (2002) correlation was found between explicit knowledge and oral production. Concerning the relationship between implicit and explicit knowledge and L2 proficiency, Han and Ellis (1998) and Elder and Ellis (2009) found that 
in the case of SLEP and IELTS, implicit and explicit L2 knowledge correlated with these two Language proficiency tests. The results of previously done studies showed that although implicit knowledge is essential to the development of L2 proficiency, the relationship between explicit knowledge and L2 proficiency is still not clear and previous investigations have found mix results concerning this relationship. As a result, further investigation is needed to probe the relationship between explicit knowledge and L2 proficiency.

\section{REFERENCES}

[1] Alderson, J. C., Clapham, C., \& Steel, D. (1997). Metalinguistic knowledge, language aptitude and language proficiency. Language Teaching Research, 1, 93-121.

[2] Bachman, L. F. (1990). Fundamental considerations in language testing. Oxford: Oxford University Press.

[3] Bowles, M. (2011). Measuring implicit and explicit linguistic knowledge: What can heritage language learners contribute? Studies in Second Language Acquisition, 33, 247-271.

[4] Briere, E. J. (1972). Are we really measuring proficiency with our foreign language tests? In H. B. Allen, \& R.N. Campbell (Eds.), Teaching English as a second languages: A book of readings (2nd Ed.). New York: McGraw-Hill Book Company.

[5] Canale, M. (1983). From communicative competence to communicative language pedagogy. In Richards, J. C., \& Schmidt, R. W. (Eds.), Language and Communication, 2-27. London: Longman.

[6] Canale, M., \& Swain, M. (1980). Theoretical bases of communicative approaches to second language teaching and testing. Applied Linguistics, 1, 1-47.

[7] Carroll, J. B. (1961). Fundamental consideration in testing for English proficiency of foreign students. In Testing the English Proficiency of Foreign Students (pp. 31-40). Washington, D.C. Center for Applied Linguistics.

[8] Clark, J. (1975). Theoretical and technical considerations in oral proficiency testing. In S. Jones, \& B. Spolsky (Eds.), Language testing proficiency (pp. 10-24). Arlington, VA: Center for Applied Linguistics.

[9] Douglas, D. (2001) Performance consistency in second language acquisition and language testing: A conceptual gap. Second Language Research 17, 442-456.

[10] Elder, C. (2009). Validating a test of metalinguistic knowledge. In R. Ellis, S. Loewen, C. Elder, R. Erlam, J. Philp, \& H. Reinders, Implicit and explicit knowledge in second language learning, testing and teaching (pp. 113-138). Bristol, UK: Multilingual Matters.

[11] Elder, C., \& Ellis, R. (2009). Implicit and explicit knowledge of L2 and language proficiency. In R. Ellis, S. Loewen, C. Elder, R. Erlam, J. Philp, \& H. Reinders, Implicit and explicit knowledge in second language learning, testing and teaching (pp. 167193). Bristol, UK: Multilingual Matters.

[12] Elder, C., \& Manwaring, D. (2004). The relationship between metalinguistic knowledge and learning outcomes among undergraduate students of Chinese. Language Awareness, 13, 145-162.

[13] Elder, C., Warren, J., Hajek, J., Manwaring, D., \& Davies, A. (1999). Metalinguistic knowledge: How important is it in studying a language at university? Australian Review of Applied Linguistics 22, 81-95.

[14] Ellis, R. (1991). Grammaticality judgments and second language acquisition. Studies in Second Language Acquisition, 13 (2), 161-186.

[15] Ellis, R. (2005). Measuring implicit and explicit knowledge of a second language. A psychometric study. Studies in Second Language Acquisition, 27, 141-172.

[16] Ellis, R., Loewen, S., Elder, C., Erlam, R., Philp, J., \& Reinders, H. (2009). Implicit and explicit knowledge in second language learning, testing and teaching. Bristol, UK: Multilingual Matters.

[17] Farhady, H. (1983). On the plausibility of the unitary language proficiency factor. In W. J. Oller, (Ed.), Issues in langauge testing research (pp. 11-28). Rowely, MA: Newbury House.

[18] Han, Y., \& Ellis, R. (1998). Implicit knowledge, explicit knowledge and general language proficiency. Language Teaching Research, 2, 1-23.

[19] $\mathrm{Hu}, \mathrm{G}$. (2002). Psychological constraints on the utility of metalinguistic knowledge in second language production. Studies in Second Language Acquisition, 24, 347-386.

[20] Hymes, D. H. (1972). On Communicative Competence. In Pride, J. B., \& Holmes, J. (Eds.), Sociolinguistics, $269-293$. Baltimore, USA: Penguin Education, Penguin Books Ltd.

[21] Krashen, S. (1981). Second Language Acquisition and Second Language Learning. Oxford: Pergamon.

[22] Krashen, S. D. (1982). Principles and Practice in Second Language Acquisition. Oxford: Pergamon.

[23] Lado, R. (1961). Language testing: the construction and use of foreign language tests. New York: McGraw Hill.

[24] McArthur, T. (1992). Oxford Companion to the English Language, Oxford, UK: Oxford University Press.

[25] Oller, J. (1979). Language Tests at School. London: Longman.

[26] Renou, J. (2001). An examination of the relationship between metalinguistic awareness and second-language proficiency of adult learners of French. Language Awareness, 10, 248-267.

[27] Roehr, K. (2008). Metalinguistic knowledge and language ability in university-level L2 learners. Applied Linguistics, 29, 173199.

[28] Schmidt, R. (2001). Attention. In P. Robinson (ed.), Cognition and Second Language Instruction (pp.3-32). Cambridge: Cambridge University Press.

[29] Sorace, A. (1985). Metalinguistic knowledge and language use in acquisition-poor environments. Applied Linguistics, 6, 239254.

[30] Thomas, M. 1994. Assessment of L2 proficiency in second language acquisition research. Language Learning 44: 307-336.

[31] White, J., \& Ranta, L. (2002). Examining the interface between metalinguistic task performance and oral production in a second language. Language Awareness, 11, 259-290. 
Bahareh Esteki received her BA degree in English Literature from the University of Isfahan in 2010. She is currently an MA student in Teaching English as a Foreign Language (TEFL) at the University of Isfahan. Her areas of interest include implicit and explicit knowledge, metalinguistic and metalingual knowledge. 